\title{
O RETORNO ESCOLAR NA IDADE ADULTA POR MULHERES DO CENTRO EDUCACIONAL DE JOVENS E ADULTOS DE SINOP-MT
}

\author{
THE RETURN OF SCHOOL IN THE OLD AGE BY WOMEN OF THE \\ EDUCATIONAL CENTER OF ADULT AND YOUTH EDUCATION IN SINOP-MT
}

\author{
Patrícia da Silva Oliveira ${ }^{1}$ \\ Tânia Pitombo de Oliveira ${ }^{2}$
}

"Mas afinal o que querem as mulheres?!"

(Sigmund Freud)

Resumo: O objetivo desse trabalho é apresentar de que forma o espaço escolar significa para um grupo de mulheres da Educação de Jovens e Adultos. Nos aliamos à Análise de Discurso Materialista Histórica. A pesquisa é de cunho qualitativo e a coleta de dados efetivou-se por meio de entrevista semiestruturadas. Os sujeitos pesquisados são três mulheres estudantes do Centro Educacional de Jovens e Adultos, da cidade de Sinop-MT. Consideramos que a ruptura escolar ocorreu comumente entre as entrevistadas por meio do casamento e que o retorno escolar significa, para elas, o recomeço e o desejo pela ascensão social.

Palavras-chave: Educação de Jovens e Adultos; espaço escolar; mulher.

Abstract: The objective of this work is to present in what way the school space means for a group of women of adult and youth education (AYE). We are allied to Historical Materialist Discourse Analysis. The research is of a qualitative nature and the data collection was carried out by means of semi-structured interviews The research subjects are three women students of adult and youth education Center, the city of Sinop-MT. We consider that school rupture occurred commonly among those interviewed through marriage and that the school return means, for them, the beginning and the desire for social advancement.

Keywords: Education of Youth and Adults; school space; woman.

\section{Introdução}

Atualmente, é possível observar, por meio dos canais midiáticos, algumas discussões referentes às mulheres, dentre elas, a legalização do aborto, o salário desigual comparado ao dos homens, o número de estudantes do sexo feminino superior ao do sexo masculino nas universidades e em algumas instituições escolares, para citar algumas.

\footnotetext{
${ }^{1}$ Universidade Estadual do Mato Grosso (UNEMAT). E-mail: patyveridiano.unemat@ gmail.com

2 Doutora em Linguística pela Universidade Estadual de Campinas. Professora da Universidade Estadual do Mato Grosso (UNEMAT), onde atua no Programa de Pós-graduação em Letras e no ProfLetras. E-mail: taniapitombo@gmail.com
} 
Entremeio às referidas discussões, nos chama a atenção o número excessivo de mulheres que retornam ao espaço escolar na idade adulta. Neste contexto, buscamos na prática discursiva de um grupo de mulheres estudantes do Centro Educacional de Jovens e Adultos (CEJA), localizado na cidade de Sinop-MT, compreender os efeitos de sentido do referido espaço escolar para as então entrevistadas.

Para tanto, Orlandi (2006) afirma que não há como dissociar o social da história, por isso, ao investigar a posição sujeito mulher em contexto da sala aula, buscamos, na construção da história escolar, o lugar ocupado pelos sujeitos em questão, como também, o processo da legalização do ensino para jovens e adultos.

Dessa forma, no primeiro tópico, 'Análise de Discurso Materialista Histórica' discorremos acerca das bases teóricas e analíticas que sustentam a nossa pesquisa. A seguir abordamos brevemente sobre a 'Educação de Jovens e Adultos no Brasil.' . No próximo tópico, 'O alunado feminino: "Bela, recatada e do lar", discutimos acerca da sociedade colonial e os subsequentes períodos relacionados à educação feminina. Situamos, também, no tópico 'Condições de produção', os dizeres desta pesquisa.

Para iniciar a análise, no tópico 'Vozes femininas da pesquisa: os percalços e a desistência escolar', a partir da voz das entrevistadas, observamos relatos de dificuldades e consequente desistência escolar. Já no tópico, 'O retorno escolar na idade adulta', identificamos as marcas de significação da sala aula para as referidas mulheres. Por fim, nas 'Considerações finais', pontuamos as informações mais relevantes de todo este enredamento de sentidos.

\section{Análise de Discurso Materialista Histórica}

O presente escrito está alicerçado na Análise de Discurso Materialista Histórica, nesse viés, torna-se relevante apresentarmos os conceitos que utilizaremos no percurso teórico e analítico. Primeiramente, cabe refletirmos como surgiu análise de discurso (AD).

Segundo Orlandi (2003, p. 18) "nos anos 60, a AD se constitui no espaço de questões criadas pela relação entre três domínios disciplinares que são ao mesmo tempo uma ruptura com o Século XIX: a linguística, o marxismo e a psicanálise." Nesse sentido, "não se dicotomiza tampouco o social e o histórico, ou o necessário e o casual. Não se visa um objeto total nem uma teoria onipotente que dê conta de "tudo" (ORLANDI, 2002, p. 3). 
Posto isso, a AD não concebe a transparência e a neutralidade das ações sociais, todos os processos estão articulados à questões ideológicas e discursivas, condicionando assim, o que pode e deve ser dito (PÊCHEUX, 1997). Nessa perspectiva, a origem dos discursos não são provindas dos sujeitos que os enunciam, temos nisto um processo de assujeitamento ideológico. Brandão (2004, p. 105) discorre que o assujeitamento ideológico:

Consiste em fazer com que cada indivíduo (sem que ele tome consciência disso, mas, ao contrário, tenha a impressão de que é o senhor de sua própria vontade) seja levado a ocupar seu lugar, a identificar-se ideologicamente com grupos ou classes de uma determinada formação social. É o mesmo que interpelação ideológica.

Esses processos discursivos não são isolados, estão em constante movimento. Nesse prisma, temos nesse assujeitamento o esquecimento número $1^{3}$, ou seja, o sujeito tem a ilusão de que seu dizer é originário de si mesmo, porém, tudo já está imerso no contexto que o circunda, daí pensamos a linguagem ligada a exterioridade e interpelação ideológica (PÊCHEUX, 1997). Sob ideologia:

A ideologia, como tenho afirmado, não é " $x$ " mas o mecanismo de produzir "x"). Não há sujeito, não há sentido sem ideologia (sem interpretação). Os sujeitos e os sentidos se constituem na/pela interpretação (pela/na ideologia), produção de efeitos metafóricos, em que a língua está investida (ORLANDI, 2002, p. 12).

O último conceito que utilizamos nas análises foi o de formação imaginárias, antes de conceituar, convém elucidar que, essas noções teóricas não são separadas em caixinhas, todas as noções da análise de discurso se 'movimentam' nos discursos. Por isso, não podemos dizer que algum fato se 'deve' ao funcionamento somente das formações imaginárias, mas sim, de várias articulações. Pêcheux (1997, p. 82) aponta que as formações imaginárias "designam o lugar que A e B se atribuem cada um a si e ao outro, a imagem que eles se fazem de seu próprio lugar e do lugar do outro."

Destarte, é sobre a égide dessa disciplina que buscamos transitar entre as vozes das alunas participantes da pesquisa, analisando os efeitos de sentido dos discursos em curso.

\footnotetext{
3 “[...] apelamos para a noção de 'sistema inconsciente' para caracterizar um outro 'esquecimento', o esquecimento $n^{o} 1$, que dá conta do fato de que o sujeito-falante não pode, por definição, se encontrar no exterior da formação discursiva que o domina. (PECHÊUX, 1997, p. 173, grifo do autor).
} 


\subsection{Educação de Jovens e Adultos no Brasil}

Ao propormos refletir acerca dos processos de significação do espaço escolar para um grupo de mulheres da Educação de Jovens e Adultos (EJA), consideramos necessário fazer um breve resgate histórico da trajetória desse segmento, haja vista que "marcado espacial e temporalmente, o sujeito é essencialmente histórico" (BRANDÃO, 2012, p. 58).

Já em 1824 foi garantida, oficialmente, na constituição brasileira a gratuidade do ensino a todas as classes sociais. Todavia:

\footnotetext{
Sem a exigência de conclusão do curso primário para o acesso a outros níveis, a elite educa seus filhos em casa, com preceptores. Para os demais seguimentos sociais, o que resta é a oferta de pouquíssimas escolas cuja atividade se acha restrita à instrução elementar: ler, escrever e contar (ARANHA, 1996, p. 155).
}

Assim, as leis educacionais que explicitavam a manutenção da ordem e um caráter emergencial, não conseguiam atender as necessidades da população, visto que o número de escolas era insuficiente para comportar a demanda e os professores careciam de qualificação. Deste modo, "a taxa de analfabetismo no Brasil atingia em 1890 a cifra de $67,2 \%$, herança do período imperial que a República não conseguira reduzir senão a 60,1\%, até 1920" (ARANHA, 1996, p. 155).

Esse cenário aponta para uma visão da escola como uma possível reprodutora da desigualdade social. Nesse viés, Orlandi (2003, p. 22) afirma que:

[...] a escola é a sede da reprodução cultural e o sistema de ensino é a solução mais dissimulada para o problema de transmissão de poder, pois contribui para a reprodução da estrutura das relações de classe dissimulando, sob a aparência da neutralidade, o cumprimento dessa função.

Sobre esse prisma, no século XX, para combater tal relação de força e poder desigual entre classes, a Proposta Curricular para a Educação de Jovens e Adultos (PC) (2002, p. 13) argumenta que vários movimentos procuraram lutar em favor da qualificação dos cidadãos menos favorecidos, "nessa época, o Decreto n. ${ }^{0}$ 16.782/A, de 13 de janeiro de 1925, conhecido como Lei Rocha Vaz, ou Reforma João Alves, estabeleceu a criação de escolas noturnas para adultos" (BRASIL, 2002, p. 13).

Contudo, "foi apenas na década de 40 que a educação de jovens e adultos se firmou como questão de política nacional, por força da Constituição de 1934” (BRASIL, 2002, p.14), garantindo o acesso gratuito de todo cidadão ao ensino primário. 
APC (2012, p. 170) alerta que "atender a instituição da EJA exige compromisso com a cidadania e com a emancipação" logo, a responsabilidade dos educadores é de serem facilitadores na construção do conhecimento junto ao aluno/cidadão.

Nesta perspectiva, procuramos, neste trabalho, compreender os efeitos de sentido desse espaço de significação para um grupo que, por variados motivos, esteve privado de ser inserido na escola, as mulheres. Para tanto, situaremos, no próximo tópico, a posição ocupada por esses sujeitos dentro e fora da sala de aula.

\subsection{0 alunado feminino: "Bela, recatada e do lar"4}

A contemporaneidade prenuncia avanços científicos e tecnológicos, além do rompimento das barreiras culturais em um mundo globalizado. Tais 'evoluções' parecem causar o entendimento de um sujeito livre das dimensões geográficas e de pensamento.

No entanto, Brandão (2012) afirma que o sujeito é dividido, clivado, cindido, na medida em que sua fala se articula com o seu inconsciente, portanto, a ele desconhecido. Descentrado, pois a descoberta do inconsciente desloca o sujeito do seu centro. Como também, o sujeito é efeito de linguagem, haja vista que, na perspectiva de Lacan, o inconsciente é constituído pela/na linguagem e esta é construída por outros discursos. Dessa forma:

[...] o falante, ao explicitar a presença do outro através das marcas da heterogeneidade mostrada, expressa no fundo seu desejo de dominância. Isto é, movido pela ilusão do centro, por um processo de denegação em que localiza o outro e delimita o seu lugar, o falante pontua o seu discurso, numa tentativa de "circunscrever e afirmar o um" (BRANDÃO, 2012, p. 69).

Nesse prisma, a busca pela centralização presente no discurso midiático, ao retratar a mulher contemporânea como 'livre' e 'empoderada', por vezes, se contradiz com alguns discursos institucionais - como ainda parece ser o caso da Instituição Igreja - de uma mulher destinada ao lar. Nesse sentido, no tecer da história, Perrot (1995, p. 13) afirma que:

Até o século XIX, faz-se pouca questão das mulheres no relato histórico, o qual, na verdade, ainda está pouco constituído. As que aparecem no relato dos cronistas são quase sempre excepcionais por sua beleza, virtude, heroísmo ou, pelo contrário, por suas intervenções tenebrosas e nocivas, suas vidas escandalosas. A noção de excepcionalidade indica que o estatuto vigente das mulheres é o do silêncio que consente com a ordem.

\footnotetext{
${ }^{4}$ A frase: "Bela, recatada e do lar", foi estampada na capa da Revista Veja no de 2016, no qual, fazia referência a Marcela Temer esposa do então presidente do Brasil Michel Temer. Tal expressão ocasionou várias manifestações nas redes sociais contrárias à mensagem da então capa de revista.
} 
Nesse caminho, tendo em vista que, de acordo com Orlandi (2000, p. 46), “o indivíduo é interpelado em sujeito pela ideologia para que se produza o dizer", e essa segundo Brandão (2012, p. 24) "é a maneira pela qual os homens vivem a sua relação com as condições reais de existência, e essa relação é necessariamente imaginária”, o lugar ocupado pelas mulheres no período colonial, historicamente, foi a de mãe e dona de casa.

Para Ribeiro (2000, p. 79), de "500 a 1822 -, período em que o Brasil foi colônia de Portugal, a educação feminina ficou geralmente restrita aos cuidados com a casa, o marido e os filhos". Tal concepção, conforme afirma Ribeiro (2000, p. 79), é o reflexo da tradição ibérica em Portugal no qual "o sexo feminino fazia parte do imbecilitussexus, ou sexo imbecill”.

Nesse cenário, tomando como pressuposto a noção de formação discursiva entendida como "aquilo que numa formação ideológica dada - ou seja, a partir de uma posição dada determina o que pode e deve ser dito" (ORLANDI, 2000, p. 43), ao sujeito mulher era negado não somente o ingresso no espaço escolar, mas a ela era reserva do lugar no silêncio.

Por esse viés, “Gonçalo Trancoso, poeta português muito lido pelos homens lusos entre 1560 e 1600, afirmava que a mulher não tinha necessidade de ler e escrever e, se possível não deveria falar" (RIBEIRO, 2000, p. 79). Tal imagem construída acerca do comportamento e educação feminina foi reproduzida no Brasil. Assim, o ensino das letras no período de colonização era restrito aos homens, tanto nativos quanto filhos de colonos.

Contudo, os índios, descontentes com a exclusão escolar de suas companheiras, "alegavam que, se a presença e assiduidade feminina era maior nos cursos de catecismo, porque também elas não podiam aprender a ler e escrever?”(RIBEIRO, 2000, p. 80). Neste contexto, o padre Manoel de Nóbrega escreveu uma carta para a então rainha de Portugal, Dona Catarina, para que permitisse que as indígenas fossem alfabetizadas, porém o pedido foi recusado.

Tal exclusão escolar parece não ter sofrido alterações com a presença da realeza lusa em 1808, haja vista que "Debret dizia que desde a chegada da Corte ao Brasil tudo se preparara, mas nada de positivo se fizera em prol da educação da jovem brasileira” (RIBEIRO, 2000, p. 89, 90). Nesse caminho, embora legalmente tenha sido estabelecida, em 1827, a "escolas de primeiras letras" por toda a província, a realidade demonstrava não condizer com a lei, pois:

Até que ponto era imperativo saber ler e escrever ou conhecer as quatro operações? Naquela sociedade escravocrata e predominantemente rural, em que latifundiários e coronéis teciam as tramas políticas e silenciavam agregados, mulheres e crianças, os arranjos sociais se faziam, na maior parte das vezes, por acordos tácitos, pelo submetimento ou pela palavra empenhada (LOURO, 2004, p. 444). 
A partir do exposto, comungamos com a reflexão de Orlandi (2003, p. 263-264) de que no ato de silenciar "às relações de poder interessa menos calar o interlocutor do que obrigá-lo a dizer o que se quer ouvir". Na mesma direção, também às mulheres que pertenciam às classes 'abastadas' eram silenciadas em um ensino diferenciado dos homens, pois além das aulas acerca da matemática básica, francês e piano,

\begin{abstract}
As habilidades com a agulha, os bordados, as rendas, as habilidades culinárias, bem como as habilidades de mando das criadas e serviçais, também faziam parte da educação das moças; acrescida de elementos que pudessem torná-las não apenas uma companhia mais agradável ao marido, mas também uma mulher capaz de bem representá-lo socialmente (LOURO, 2004, p. 446).
\end{abstract}

Dessa forma, compreendemos que o silenciamento feminino na sociedade patriarcal demonstra funcionar como regimento do dizer desse público, assim, “o domínio da casa era claramente o seu destino e para esse domínio as moças deveriam estar plenamente preparadas" (LOURO, 2004, p. 446).

Atualmente a PC (2002, p. 75) observa que:

É marcante [...] a presença feminina, em especial de donas-de-casa. Pode-se conjeturar que a necessidade de trabalhar por assumir a responsabilidade pelo sustento da família, ou para compor o orçamento doméstico, nos casos de desemprego do marido tem levado mulheres de volta aos bancos escolares, em busca de uma formação mais compatível com as exigências do mercado de trabalho.

Com base nesta reflexão, nossa análise inicia a partir da voz dessas mulheres pobres e donas de casa. Por esse viés, na cidade de Sinop-MT, o Centro Educacional de Jovens e Adultos procura atender ao referido público nos três períodos, matutino, vespertino e noturno. A seguir dissertaremos acerca do referido lócus de pesquisa, que compreende as condições dos discursos em voga.

\title{
2 Condições de produção
}

Tendo em vista que nos filiamos a teoria Materialista da Análise de Discurso, é relevante compreender que, de acordo com Orlandi (2006, p. 15), "o sujeito da análise de discurso não é o sujeito empírico, mas a posição sujeito projetada no discurso", dessa forma, salientaremos as condições de produção do estudo em foco.

Orlandi (2000, p. 30) afirma que as condições de produção "compreendem fundamentalmente os sujeitos e a situação", assim, os participantes da pesquisa são três 
mulheres com a faixa etária entre 35 e 47 anos de idade. As referidas participantes são estudantes do Centro Educacional de Jovens e Adultos da cidade de Sinop-MT.

Para a investigação, foi utilizado um roteiro de perguntas semiestruturadas e a entrevista foi gravada em forma de áudio. Ressaltamos, também, que para manter a descrição da identidade das participantes, as nomeamos ficticiamente: Maria das Dores (47 anos), Maria das Graças (46 anos) e Maria Aparecida (35 anos).

\section{Vozes femininas da pesquisa: os percalços e a desistência escolar}

A partir desse entrelace histórico, nos propomos a compreender as significações do espaço escolar para um grupo de sujeitos que por muito tempo esteve à margem da educação, as mulheres. Dessa forma, nos respaldamos em Orlandi (2006, p. 15), ao compreender o discurso como "efeitos que resultam da relação de sujeitos simbólicos que participam do discurso, dentro de circunstâncias dadas." Buscamos, por meio das vozes dessas alunas mulheres, identificar as marcas discursivas dos efeitos que constituem tais falas.

Nossa inquietação parte de averiguar as condições predominantes para que as referidas alunas interrompessem os estudos ou iniciasse a sua formação na idade adulta:

- Eu estudei mas aí quando tava já de 16 anos 14, 15 anos eu já não estudei mais né? Que a gente morava na roça né? E era um lugar assim muito...a gente era muito pobre pobre pobre e a gente num tinha como...se fosse pra ir pra estudar com fome né? A gente não ia né? A mãe não deixava né? 'Prefiria' ficar em casa né? Porque tinha vezes que não tinha nem merenda aí eu peguei e...a minha mãe, meu pai preferia que a gente ficasse em casa né? Mas aí eu fiquei e perdi a oportunidade de estudar então agora eu venho estudar agora né? (Maria das Dores)

- Estudei...na realidade eu entrei na aula com seis anos de idade nem era matriculado aquele tempo né? não tinha prézinho daí estudei um ano aí depois no próximo ano foi que meu pai fez a matrícula né? só que eu faltava muito...não me interessava e a gente apanhava muito na 
escola...eu e meu irmão né... daí a gente...eu falta...a gente faltava demais aí eu reprovei muito muito muito né? Depois, morando em sítio, morando longe [...] daí eu nunca me interessei também muito assim né? Aí passou o tempo daí eu casei daí consegui concluir só até a $2^{\circ}$ série né? aí tá, parei, daí voltei tá em 2013 eu voltei daí estudei um ano e passei pra $4^{\circ}$ sé...pra $5^{\circ}$ aí saí novamente tive que trabalhar fora aí agora que eu voltei. (Maria das Graças)

No primeiro relato, Maria das Dores relaciona a sua falta de instrução escolar na infância à 'pobreza'. Para ela, 'apanhar na escola' e a 'distância', foram alguns dos determinantes para o afastamento escolar. Neste contexto, Brandão (2012, p. 23), ancorada em Althusser, afirma que, "para manter sua dominação, a classe dominante gera mecanismo de perpetuação ou de reprodução das condições materiais, ideológicas e políticas de exploração”. Na mesma direção, Orlandi (2003, p. 206) reflete que:

Nessa perspectiva - da interpenetração das classes e da absorção das diferenças é que chegamos ao jogo de palavras existente em relação aos conceitos de "liberdade": a burguesia sempre proclama o ideal da igualdade ao mesmo tempo que organiza uma desigualdade real.

No discurso ideológico dominante, cabem as camadas superiores o estudo e ao pobre o trabalho.

Em relação ao sujeito, Orlandi (2000, p. 52) argumenta, ainda, “o fato de que ele é produto histórico, efeito de discurso que sofre as determinações dos modos de assujeitamento das diferentes formas-sujeito na sua historicidade e em relação às diferentes formas de poder." Dessa forma, ao Maria das Graças expressar "não me interessava”, “depois morando em sítio", se relaciona com o discurso da sociedade marcada por uma memória escravagista, no qual Louro (2004, p. 444) reflete que:

[...] não se pode esquecer que, de um modo geral, as meninas das camadas populares estavam, desde muito cedo, envolvidas nas tarefas domésticas, no trabalho da roça, no cuidado dos irmãos menores, e que essas atribuições tinham prioridade sobre qual quer forma de educação escolarizada para elas.

Com base no exposto, ao não conseguir explicar as possíveis razões da ausência de 'interesse' em participar do ambiente escolar, a entrevistada acena para o conceito de esquecimento 1 que "é o que dá conta do fato de que o sujeito falante não pode, por definição, se encontrar no exterior da formação discursiva que o determina" (ORLANDI, 2006, p. 22). 
Sendo assim, não seria possível despertar o desejo de instrução nas alunas sitiantes ou roceiras, haja vista que, de acordo com as condições históricas, a elas eram reservados outros afazeres.

Como observado, alguns percalços impossibilitaram que as alunas entrevistadas obtivessem em tempo hábil a formação escolar. Por isso, questionamos a essas mulheres se houve a oportunidade do retorno escolar mais cedo:

- Não...aí eu tinha 16 e casei com 17 né? aí pronto...ai não estudei mais mesmo né porque eu tive a oportunidade... assim...do marido não deixar estudar né? Com aquele ciúme né? Então aí a gente não estudava né? porque gente do sítio né?...tão do sítio como hoje em dia que acontece né? A maioria das mulheres não estuda porque o marido não gosta...então nisso aí fico... a gente não estuda e hoje tá fazendo muita falta...muita muita falta mesmo. (Maria das Dores)

- Tive, mas não tive interesse de voltar [...] porque foi assim... porque também eu era casada, casei com 17 anos e daí meu esposo nunca me apoio muito né? Meu ex marido nunca me apoio muito pra estudar e daí eu também nunca...nunca assim sabe nunca me interessei pra estudar. (Maria das Graças)

- Por que casei... filhos...e aí sempre adiando...sempre o ano que vem eu vou...o ano que vem eu vou... e nunca voltava. Trabalhava fora também aí meus horários de serviço eu entrava às 6 da manhã e saia 5:30, 6:30 da tarde. (Maria Aparecida)

Nos três relatos acima, é possível observar que o mesmo verbo de ação se repete: 'casei'. Neste contexto, Orlandi (2006, p. 22) compreende que "todo dizer se acompanha de um dizer já dito e esquecido que o constitui em sua memória." Por isso, na construção histórica, "ser mãe, esposa e dona de casa era considerado o destino natural das mulheres" (BASSANEZI, 2004, p. 609).

A partir da referida memória discursiva presente nas vozes das alunas mulheres, averiguamos, também, que Maria das Dores expressa que "A maioria das mulheres não estuda porque o marido não gosta", na mesma direção, Maria das Graças relata "meu esposo 
nunca me apoio muito né?". Sobre esse prisma, Orlandi (2000, p. 40) reflete que "não são os sujeitos físicos nem os seus os seus lugares empíricos como tal, isto é, como estão inscritos na sociedade, e que poderiam ser sociologicamente descritos, que funcionam no discurso, mas suas imagens que resultam de projeções.” Por esse caminho, é possível observar, na fala das referidas alunas, uma imagem definida da mulher que não estuda porque o homem não gosta.

Já Maria Aparecida acrescenta que "Trabalhava fora". A partir dessa afirmação, refletimos que embora 'trabalhar fora' passou a fazer parte do cotidiano de muitas mulheres 'modernas', esse fato não as dispensou dos serviços domésticos e do compromisso com o marido e com os filhos. Neste contexto, Orlandi (2006, p. 15) considera que "uma palavra, uma expressão [...] não existe em si mesmo [...] mas ao contrário é determinado pelas posições ideológicas que estão em processo sócio-histórico.” Por esta ótica:

O casamento-modelo definia atribuições e direitos distintos para homens e mulheres. Tarefas domésticas como cozinhar, lavar, passar, cuidar dos filhos e limpar a casa eram consideradas deveres exclusivamente femininos. Dentro de casa, os homens deveriam ser solicitados apenas a fazer pequenos reparos. [...] as mulheres não têm o direito de questionar a divisão tradicional de papéis e exigir a participação do marido nos serviços do lar comprometeriam, com essa atitude, o equilíbrio conjugal (BASSANEZI, 2004, p. 626).

Nesta perspectiva, a legislação brasileira de 1988 garante o acesso de ‘todos’ à educação e os canais midiáticos anunciam a 'liberdade' das ações femininas, mas, por meio da voz do grupo entrevistado, para a mulher, o papel de mãe e de esposa antecede todos os outros. Nesse intento, no tópico que se segue, nos interessa compreender de que forma a volta à escola significa para o referido grupo.

\subsection{O retorno escolar na idade adulta}

A partir dos relatos de luta e desafios, questionamos as alunas pesquisadas o que as motivaram retornar à sala de aula na idade adulta:

- Decidi voltar por causa que faz muita falta no emprego... pro trabalho. (Maria das Dores) 
- Porque eu quero...quero melhorar minha vida quero fazer uma faculdade de Gastronomia né? daí a gente precisa terminar né? (Maria da Graça)

- Eu voltei porque eu decidi né...eu na verdade perdi uma oportunidade de serviço que tava na minha mão por causa do meu estudo. (Maria Aparecida)

$\mathrm{Na}$ fala das alunas mulheres identificamos as marcas: "muita falta no emprego", "quero melhorar minha vida" e "perdi uma oportunidade de serviço". Assim, observamos que a instrução escolar aparece relacionada à ascensão social, ou seja, quem estuda consegue o melhor emprego e consequentemente estabilidade financeira.

Sobre esse prisma educacional, intencionamos averiguar qual a importância do espaço escolar para as entrevistadas:

- Muito muito muito...nossa! porque que eu vou fazer né? então eu fiquei com problema de depressão ai minha filha falou: "Mãe vai estudar né?" aí eu vim estudar e... nossa! Foi que nem remédio pra mim sabe? Nossa! Muito bom mesmo...eu não quero desistir como tão falando que o EJA vai fazer né se não tiver 15 alunos na sala então eu to pedindo a Deus que isso não acontece porque se for pra gente estudar 'onlaine' como quem não sabe quase nada vai estudar que jeito? E nossa sala não é só mulher de anos né? têm jovens que estuda... então nossa! Eu to muito animada mesmo e não quero desistir mesmo sabe? Não quero mesmo desistir de estudar é muito bom faz muita falta hoje em dia a gente eu vejo muitos jovens não vem pra aula porque fica levando tudo as coisas na brincadeira né? às vezes eu falo: "vocês não sabe quanto que vai fazer falta pra vocês depois" porque eu penso 'ni' mim porque quanto que eu to arrependida de não ter estudado antes de não ter oportunidade de estudar então hoje tá fazendo muita falta mesmo até a gente vai ver um trabalho um serviço assim e povo: "ah que série você tem?” e a gente fica meio assim de falar né? Então não é fácil é difícil. (Maria das Dores) 
- Ah eu acho muito importante né? Por assim eu já aprendi muito né? a gente aprendi bastante...você estudando abre a sua mente né é outra...outra coisa...outra visão que a gente tem.[...] daí a gente se separou depois que a gente se separou eu falei: "gente eu quero voltar" e eu gosto muito de cozinha né? falei: “não! eu quero fazer uma faculdade de gastronomia" mas pra mim fazer gastronomia eu tenho que estudar né? daí foi onde que eu voltei a estudar. Muito bom né...aqui é muito bom aqui ...o ensino...tudo aqui é muito bom. Pena assim que as pessoas faltam muito né...os alunos... (Maria das Graças)

- É uma válvula de escape que a gente tem né pra poder...porque se não fosse né. Pra quem não teve oportunidade né...às vezes trabalha o dia inteiro... não tem condições de estar aqui. Vai me ajudar bastante né...profissão...cursos que eu possa ta fazendo mais pra frente né... (Maria Aparecida)

Na fala da aluna Maria das Dores, destacamos as expressões, "Foi que nem remédio", e na voz de Maria das Graças "depois que a gente se separou eu falei: "gente eu quero voltar". Dessa maneira, averiguamos que a escola, para as entrevistadas, significou um recomeço de vida. Nessa via, Orlandi (2000, p. 52) afirma que "nem sujeitos nem sentidos estão completos, já feitos, constituídos definitivamente. [...] essa incompletude atesta a abertura do simbólico, pois a falta é também o lugar do possível”.

Neste cenário, as Orientações Curriculares (2010, p. 171) refletem que:

Na EJA a preocupação não é apenas com a trajetória escolar, mas principalmente com trajetórias pessoais e humanas: como homens, mulheres, indígenas, negros e negras, trabalhadores que vivem experiências humanas em todos os espaços da vida social e como interferir para que possam ter consciência da construção social que realizam e da perspectiva cidadã a que têm direito.

Além disso, que participam do referido espaço escolar, exprimem sonhos e expectativas, como podemos verifica na voz de Maria das Graças: "não! eu quero fazer uma faculdade de Gastronomia", e da Maria Aparecida: "Vai me ajudar bastante né...profissão...cursos que eu possa ta fazendo mais pra frente né...". 
Neste contexto, Orlandi (2006, p. 16) pondera que "as relações de força, o lugar social do qual falamos marca o discurso com a força da locução que este lugar representa.” Assim, o discurso descrito a partir da posição sujeito mulher aparece marcado historicamente por um país colonizado, tradicionalmente cristão e patriarcal. E, embora essas mulheres tenham a possibilidade de ocupar um lugar no trabalho, nas escolas e nas universidades, a imagem feminina ainda se relaciona, nos discursos analisados, a casa, aos filhos e ao marido.

\section{Considerações finais}

O esboço histórico da Educação de Jovens e Adultos no Brasil demonstra que no decorrer de sua história educacional esses sujeitos estiveram por muito tempo à margem da educação igualitária, sendo que, este seguimento possuía um caráter emergencial e provisório. Ao que concerne ao alunado feminino, a exclusão escolar foi realidade por muitos anos e quando permitido ingresso, a finalidade era de formar uma boa esposa e mãe.

A partir do entrelace da história com a voz das alunas mulheres, consideramos que a formação imaginária da mulher ocupando sempre a posição de mãe, dona de casa e esposa se relaciona com o que já foi dito, porém esquecido, pela tradição dos colonos portugueses. Nessa direção, por meio da análise de dados, observamos que embora atualmente as participantes da pesquisa ocupem outras posições, a prática discursiva se relaciona, ainda, com a casa, marido e filhos.

Ao que concerne ao retorno escolar, analisamos que as marcas do anseio pela ascensão social e o desejo pelo recomeço aparecem no relato das entrevistadas corroborando a incompletude do sujeito. Dessa forma, entendemos que a Educação de Jovens e Adultos ao abrigar as muitas Marias brasileiras se compromete não apenas com a instrução escolar, mas com a autoestima e qualidade de vida de mulheres carregadas de história.

\section{Referências}

ARANHA, Maria Lúcia Arruda. História da Educação no Brasil. São Paulo: Moderna, 1996.

BRANDÃO, Helena Hathsue Nagamine. Introdução à análise do discurso. Campinas, SP: Editora Unicamp, 2012.

BASSANEZI, Carla. Mulheres dos Anos Dourados. In: PRIORE, Mary Del (org.). História das mulheres no Brasil. São Paulo: Contexto, 2004. 
BRASIL. Proposta Curricular para a educação de jovens e adultos: segundo segmento do ensino fundamental: 5 a a 8 a série. Secretaria de Educação Fundamental, 2002.

. Constituição da República Federativa do Brasil. Brasília, DF: Senado Federal:

Centro gráfico, 1988.

LOURO, Guacira Lopes. Mulheres na sala de aula. In: PRIORE, Mary Del (org.). História das mulheres no Brasil. São Paulo: Contexto, 2004.

MATO GROSSO. Secretaria de estado de Educação. Orientações Curriculares: Área de Linguagens: educação Básica. Cuiabá: Gráfica Print, 2012.

ORLANDI, Eni Puccinelli. As formas do silêncio: no movimento dos sentidos. Campinas: Ed. Unicamp, 1995.

Análise de discurso: princípios e procedimentos. Campinas: Pontes, 2000.

.A linguagem e seu funcionamento: as formas do discurso. Campinas,SP: Pontes Editores, 2005.

. Análise de discurso. In: ORLANDI, Eni Puccinelli; LAGAZZI- RODRIGUES, Suzy

(orgs.). Introdução às ciências da linguagem: Discurso e Textualidade. Campinas, SP: Pontes Editores, 2006.

PERROT, Michelle. Escrever uma história das mulheres: relato de uma experiência. Cad. Pagu, Campinas, n. 4, p. 9-28, abril. 1995.

PÊCHEUX, Michel. Análise Automática do Discurso. In: GADET, Françoise; HAK, Tony. (orgs). Por uma análise automática do discurso: introdução à obra de Michel Pêcheux. 3 ed. Campinas: Ed. da Unicamp, 1997.

RIBEIRO, Arilda Ines Miranda. Mulheres Educadas na Colônia. In: LOPES, Eliane Marta Teixeira; FILHO, Luciano Mendes de Faria; VEIGA, Cynthia Greive (Orgs.). 500 Anos de Educação no Brasil. 2. ed. Belo Horizonte, MG: Autêntica, 2000, p. 79-94. 